\title{
A Dynamic Model based on a Network of Magnetically Coupled Reluctances for Asyncrhonous Motor Fault Analysis
}

\author{
F. Pedrayes, C. H. Rojas, M. F. Cabanas, M. G. Melero, G. A. Orcajo, J. M. Cano \\ University of Oviedo - Electrical Engineering Dept. \\ Campus de Viesques s/n 33204 - Gijón, Asturias, SPAIN \\ http://www.dimie.uniovi.es
}

\begin{abstract}
The growing application of asynchronous motors in industrial processes that require high security and reliability levels has led to the development of multiple methods for early fault detection. The design and verification of these methods imply the use of complex mathematical models that allow the study of the influence produced by the machine operating conditions over the diagnosis procedure. The present paper describes a model for asynchronous motors based on a network of magnetically coupled reluctances. The aim of this model is its application to the study of the typical failures of this type of machine i. e. rotor asymmetries, airgap eccentricity, operation with an open phase etc. The dynamic properties of the model allow the simulation of the spatial evolution of all the motor variables, without neglecting complex phenomena such as magnetic saturation. Time domain analysis of airgap torque, as well as the calculation of current harmonic components are also possible. This initial study is aimed to check the accuracy and computation economy of the model. To do this, the motor is simulated under rated load operation conditions and the temporal evolution of its main electrical and mechanical variables are obtained.
\end{abstract}

\section{Key words}

Asynchronous motor, model, reluctance mesh, fault analysis

\section{Introduction}

The growing use of asynchronous motors in industrial applications has favoured the development of new diagnosis techniques commonly used in most of industrial predictive maintenance programs, [1]. The development of these new diagnosis procedures invariably implies the design of new models to simulate the evolution of the machine's variables under different failure conditions, [2], [3], [4]. The lack of knowledge about certain physical phenomena involved in the failure process restricts the use of simplifying assumptions and thus modelling task is notably complicated. Nowadays, the most frequently used, versatile and precise models are based on the Finite Element Method (FEM), [5], [6], [7], but they present the drawback of a high consumption of processing time and hardware resources. For this reason, the design of alternative modelling strategies, where a commitment between accuracy and resources consumption exists, is one of the present goals in the research on electrical machines. This paper presents a new dynamic model for the asynchronous machine oriented to the study of failures. The model is based on a network of magnetically coupled reluctances and its structure will be defined in the following sections.

\section{Magnetic Coupled Circuits Model}

The new proposed model is based on the creation of a network of magnetically coupled reluctances, [2], [4], that will be analysed according to Hopkinson Law, [8]. Once this network is built a set of differential equations where magnetic flux is the main unknown must be solved, [9], [10], [11]. In a first stage, a group of reluctances representing every portion of the magnetic core of rotor and stator are defined. The values of these reluctances are obtained from the geometrical dimensions and the physical characteristics of the magnetic laminations:

$R=\frac{L}{\mu \cdot S}$

$\mathrm{R}$ being the reluctance value, $\mu$ the magnetic material permeability, $L$ the length and $S$ the section of the magnetic core that is being represented. The value of $\mu$ is obtained from the magnetic saturation curve of the laminations. Fig. 1 shows the overall reluctance network for a motor 
with 28 bars and 36 slots. Fig. 2 is a photograph of the modelled motor.

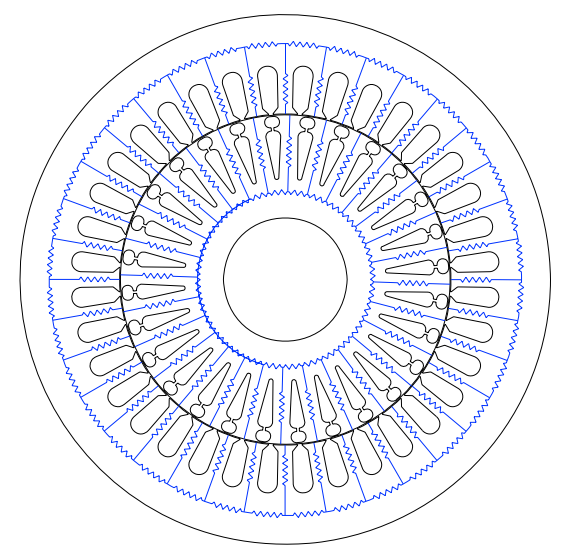

Fig. 1 Overall Reluctance Network for a 28 bar and 36 slots motor

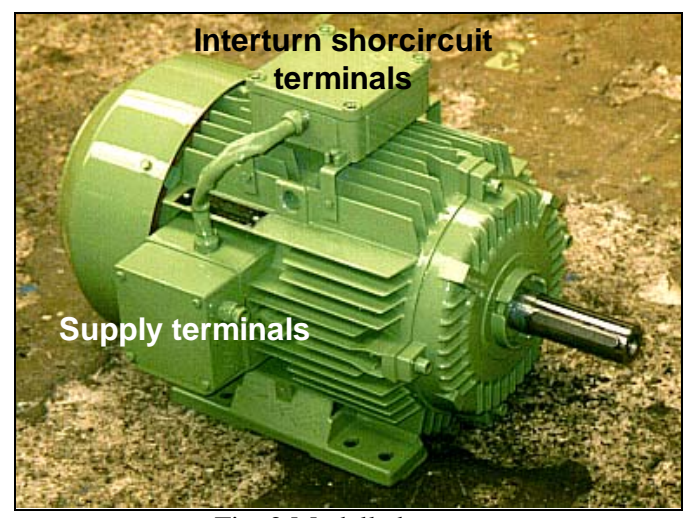

Fig. 2 Modelled motor

Between the reluctance meshes of rotor and stator an additional ring of reluctances is defined in the airgap, considering that magnetic permeability in this region is the same that in the vacuum. This reluctance ring rotates together with the rotor, sliding itself over the stator reluctance meshes. In this way, the machine's motion is simulated.

The simulation of motion implies the calculation of rotor displacement as a time function, as well as the modification, according to the turned angle, of the value of all the reluctances forming the ring in the airgap. Fig. 3 shows the network of reluctances in the airgap region. In this figure the ring of reluctances can be observed.

\section{System of Simultaneous Equations}

The mathematical resolution of the model implies solving a differential equation system with $m+n+2$ unknowns, $m$ being the number of stator slots and $n$ the number of rotor bars. The system unknowns are the magnetic fluxes in the rotor and stator meshes $(m+n)$,angular speed and the rotor turned angle. Rotor equations can be defined as follows:

$\left[I b_{i}\right]=\left[R k_{12}\right]\left[\phi_{b i}\right]-\left[R_{\text {bnestm }}\right]\left[\phi_{\text {estj }}\right] \quad \mathrm{i}=1, \ldots, 28 ; \mathrm{j}=$ $1, \ldots, 36$;

$\left[I b_{i}\right]$ : vector of rotor bar currents.

$\left[\phi_{b i}\right]$ : vector of magnetic fluxes in the rotor meshes.

$\left[\phi_{e s t j}\right]$ : vector of magnetic fluxes in the stator meshes.

$\left[R_{\text {bnestm }}\right]$ : matrix of common reluctances between rotor and stator.

$\left[R k_{12}\right]$ : matrix of common reluctances between rotor meshes.

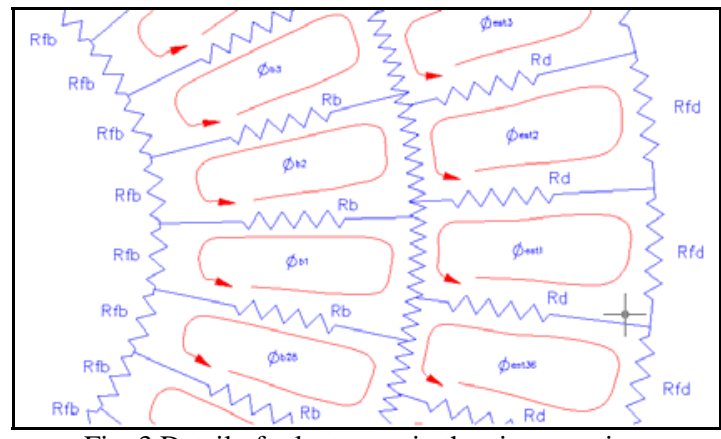

Fig. 3 Detail of reluctances in the airgap region.

Every element "Rbiestj" of the matrix [Rbnestm] represents the common reluctance between the " $i$ " rotor mesh and the " $j$ " stator mesh. The value of this reluctance depends on the turned angle and the value of the magnetic flux and saturation level of the machine. All the elements "Rbiestj" are updated in every turning step of the rotor. Rotor currents can be expressed as a function of the model unknowns as follows:

$\left[I b_{i}\right]=[A]\left[I b b_{i}\right]$

$\left[I b b_{i}\right]$ : being the vector of rotor mesh currents

(Fig. 4) and [A] the matrix of rotor current distribution. The elements in this matrix allow the calculation of the rotor bar currents as the difference between the currents of two adjacent rotor meshes. Fig. 4 is of a diagram where the relationship between rotor bar current and rotor mesh current is clearly shown.

By applying the Lenz's law it is possible to express the rotor mesh currents as a function of magnetic fluxes (model unknowns):

$[B]\left[\frac{d \phi_{b i}}{d t}\right]=[R a b]\left[I_{b b i}\right]$

$[B]$ : Distribution matrix. This matrix allows the transformation of the fluxes of every pair of rotor 
meshes into the flux of the rotor teeth, i.e. the flux linked by the $n$ tooth can be calculated as the difference between the fluxes of the rotor meshes $n+1$ and $n(\varphi n+1-\varphi n)$. Fig. 5 shows a diagram of where the teeth fluxes and rotor current meshes can be observed.

$\left[\frac{d \phi_{b i}}{d t}\right]$ : derivatives of the magnetic fluxes of every rotor mesh.

$[R a b]$ : matrix of resistances of rotor bar and endrings.

$\left[I_{b b i}\right]$ : matrix of rotor bar currents.

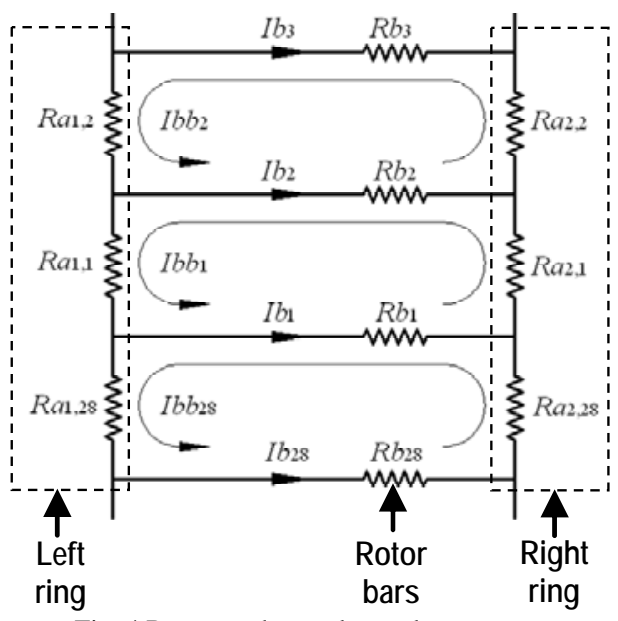

Fig. 4 Rotor meshes and rotor bar currents

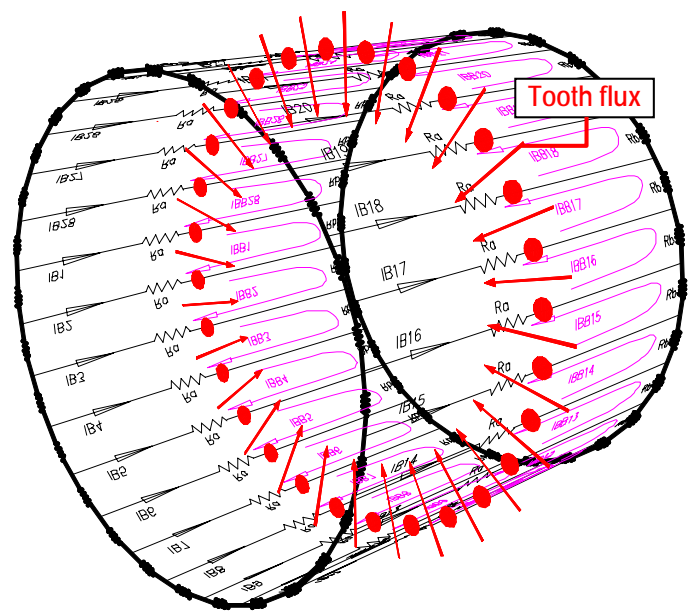

Fig. 5 Meshes and fluxes in the rotor

The substitution of equations 3 and 4 in equation 2 leads to the rotor system of simultaneous equations:

$[A]\left[R a b^{-1}\right][B]\left[\frac{d \phi_{b i}}{d t}\right]=\left[R k_{12}\right]\left[\phi_{b i}\right]-\left[R_{b n e s s t m}\right]\left[\phi_{e s t j}\right]$
This equation system is linearly dependent. To solve it the condition that the sum of all bar currents is null at any time instance is imposed. To do it Ampere's Law is applied to the closed trajectory formed by the reluctances of the rotor yoke:

$\sum_{j=1}^{28} \Re \mathfrak{R}_{j} \cdot \phi b_{j}=0 \Rightarrow \sum_{j=1}^{28} \Re_{f b_{j}} \cdot \frac{d \phi b_{j}}{d t}+\sum_{j=1}^{28} \phi_{b_{j}} \cdot \frac{d \Re b_{j}}{d t}=0$

$\Rightarrow \sum_{j=1}^{28} \Re f b_{j} \cdot \frac{d \phi b_{j}}{d t}=-\sum_{j=1}^{28} \phi b_{j} \cdot \frac{d \Re f b_{j}}{d t}$

For the stator modelling the system of simultaneous equations can be obtained in the same way that the rotor one:

$\left[\mathrm{fmm}_{\text {esti }}\right]=\left[R k_{34}\right]\left[\Phi_{\text {estj }}\right]-\left[R_{b N e s t M}^{t}\right]\left[\Phi_{b i}\right]$

$\left[R k_{34}\right]$ : being the matrix of common reluctances in the stator meshes and $\left[\mathrm{fmm}_{\text {esti }}\right]$ the vector of the magnetomotive forces in the stator slots. Magnetomotive forces are the product of the number of turns of every stator coil times the winding branch current. This vector can also be calculated as follows:

$\left[\right.$ fmm $\left._{\text {esti }}\right]=\left[K_{1}\right] \cdot\left[U_{\text {fase }}\right]+\left[K_{2}\right] \cdot\left[\frac{d \phi_{\text {estj }}}{d t}\right]$

$\left[K_{1}\right]$ and $\left[K_{2}\right]$ being constant matrixes depending on the winding configuration, $\left[U_{\text {fase }}\right]$ being the motor phase voltages and $\left[\frac{d \phi_{e s t j}}{d t}\right]$ being the time derivative of the stator mesh fluxes. Fig. 6 shows a diagram where the relationship between the branch current and the stator mesh fluxes is shown for an individual phase coil.

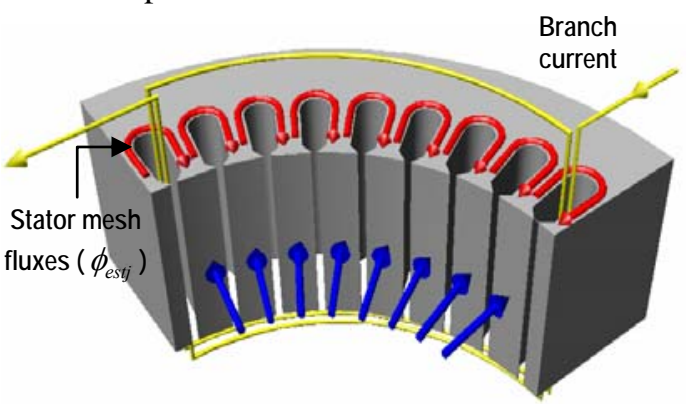

Fig. 6 Branch current and stator mesh fluxes

By substituting [8] in [7] the simultaneous equations system for the stator is obtained:

$$
\begin{aligned}
& {\left[\text { fmm }_{\text {esti }}\right]=\left[K_{1}\right] \cdot\left[U_{\text {fase }}\right]+\left[K_{2}\right] \cdot\left[\frac{d \phi_{\text {esti }}}{d t}\right]=} \\
& {\left[R k_{34}\right]\left[\Phi_{\text {esti }}\right]-\left[R_{b \text { NestM }}^{t}\right]\left[\Phi_{b i}\right]}
\end{aligned}
$$


[9]: Shows the relationship between the stator mesh fluxes, their time derivatives and the rotor mesh fluxes.

\section{Energy balance and torque calculation}

In torque calculation the principle of energy conversion is applied to the machine internal energy. The machine input power must be compensated at any instance of time by the electrical and mechanical losses and the variation with time of the stored energy (magnetic and kinetic energy). This principle can be graphically represented as Fig. 7 shows:

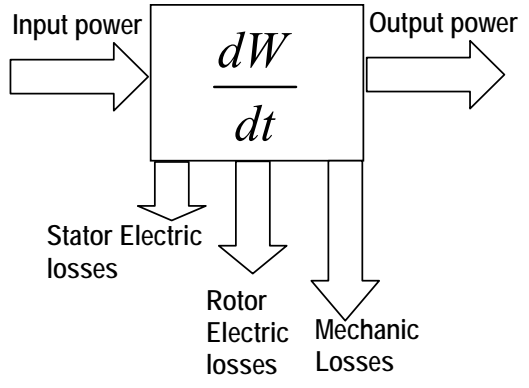

Fig. 7 Energy balance in a rotating machine

This graphical representation can be easily converted into a mathematical equation:

$\left[\begin{array}{l}\left.\begin{array}{l}\text { Input } \\ \text { power }\end{array}\right]-\left[\begin{array}{l}\text { Stator } \\ \text { Losses }\end{array}\right]-\left[\begin{array}{l}\text { Rotor } \\ \text { Losses }\end{array}\right]-\left[\begin{array}{l}\text { Mechanical } \\ \text { Losses }\end{array}\right]-\left[\begin{array}{l}\text { Output } \\ \text { Power }\end{array}\right]=\frac{\partial W}{\partial t}\end{array}[10]\right.$

All the elements in equation 10 can be expressed as a function of the model parameters:

$\left[P_{\text {INPUT }}\right]=v_{R}(t) \cdot\left[i_{R 1}(t)+i_{R_{2}}(t)\right]+$

$v_{S}(t) \cdot\left[i_{S 1}(t)+i_{S 2}(t)\right]+v_{T}(t) \cdot\left[i_{T 1}(t)+i_{T 2}(t)\right]$

$i_{i 1}(t)$ and $i_{i 2}(t)$ being the winding branch currents

for the $\mathrm{R}, \mathrm{S}$ and $\mathrm{T}$ phases (the machine winding is formed by two parallel branches).

$$
\begin{aligned}
& {\left[\begin{array}{l}
\text { Stator } \\
\text { Losses }
\end{array}\right]=R_{\text {Winding }} \cdot\left[i_{R 1}(t)^{2}+i_{R 2}(t)^{2}+\right.} \\
& \left.i_{S 1}(t)^{2}+i_{S 2}(t)^{2}+i_{T 1}(t)^{2}+i t_{2}(t)^{2}\right]
\end{aligned}
$$

$R_{\text {winding }}$ being the electrical resistance of the stator windings.

Rotor losses can be directly calculated from the electrical diagram presented in Fig. 4:

$$
\begin{aligned}
& {\left[\begin{array}{l}
\text { Rotor } \\
\text { Losses }
\end{array}\right]=\sum_{i=1}^{28} R b_{i}(t) \cdot I b_{i}(t)^{2}+} \\
& \sum_{i=1}^{28} R a_{1 i}(t) \cdot I b b_{i}(t)^{2}+\sum_{i=1}^{28} R a_{2 i}(t) \cdot I b b_{i}(t)^{2}
\end{aligned}
$$

Mechanical losses are considered as frictional losses, therefore, they are proportional to the cube of the angular speed: $\left[\begin{array}{l}\text { Mechanical } \\ \text { Losses }\end{array}\right]=k r \cdot \omega^{3}$

The output power is the product of the load torque times the angular speed. The load torque is an input data for the model that can be defined by the user as a constant or a mathematical function. In this way, any type of load, even loads with harmonics components, can be applied to the machine in order to analyse the behaviour of the motor electrical variables.

$\left[P_{\text {OUTPUT }}\right]=T_{\text {LOAD }} \cdot \omega$

The machine stored energy can be decomposed into two different terms: the rotation kinetic energy and the electromagnetic energy stored into the motor magnetic fields:

$W(t)=W_{R K}(t)+W_{M F}(t)$

$W_{R K}(t)$ being the rotation kinetic energy and $W_{M F}(t)$ the electromagnetic energy stored into the motor magnetic fields.

The rotation kinetic energy can be calculated as follows: $W_{R K}(t)=\frac{1}{2} \cdot J \cdot \omega(t)^{2}$

$J$ being the moment of inertia of rotor and driven load, measured in $\mathrm{kg} \cdot \mathrm{m}^{2}$. The instantaneous energy stored into the motor magnetic fields can be expressed as follows:

$W_{M F}=\int_{V o l} \frac{1}{2} \cdot B(\alpha, t) \cdot H(\alpha, t) \cdot d V$

In the above equation $\frac{1}{2} \cdot B(\alpha, t) \cdot H(\alpha, t)$ is the electromagnetic energy per volume unit. If this mathematical relation is applied to one of the machine tooth the result obtained for the stored energy is the following:

$W_{\text {TоOтH }}(t)=\frac{1}{2} \cdot B \cdot H \cdot V$

$V$ being the tooth volume. If the cross-section of the tooth is $S$ equation 18 can be written as follows:

$W_{\text {ТООТН }}(t)=\frac{1}{2} \cdot B \cdot H \cdot V=\frac{1}{2} \cdot B \cdot \frac{B}{\mu} \cdot S \cdot L=$
$\frac{1}{2} \cdot \frac{\phi^{2}}{S^{2}} \cdot \frac{1}{\mu} \cdot S \cdot L=\frac{1}{2} \cdot\left(\frac{L}{\mu \cdot S}\right) \cdot \phi^{2}=\frac{1}{2} \cdot \Re \cdot \phi^{2}$

$\Re$ being the tooth magnetic reluctance and $\phi$ the magnetic flux linked by the tooth at any instance of time. If the result obtained in 19 is extrapolated to the entire machine, the instantaneous energy stored in the motor magnetic fields can be computed as follows:

$W_{M F}(t)=\sum_{i=1}^{N} \frac{1}{2} \cdot \Re_{i}(t) \cdot \phi_{i}(t)^{2}$ 
In this case, $N$ is the total number of reluctances included in the model. $\mathfrak{R}_{i}(t)$ represents a single reluctance and $\phi_{i}(t)$ the flux linked by $\mathfrak{R}_{i}(t)$.

The time derivative of the total internal energy can, therefore, by expressed as follows:

$$
\begin{aligned}
& \dot{W}=\dot{W}_{R K}+\dot{W}_{M F}=J \cdot w \cdot \frac{d w}{d t}+ \\
& \sum_{i=1}^{N} \Re_{i} \cdot \phi_{i} \cdot \frac{d \phi_{i}}{d t}+\sum_{i=1}^{N} \frac{1}{2} \cdot \phi_{i}^{2} \cdot \frac{d \Re_{i}}{d t}
\end{aligned}
$$

In this way, a new differential equation that represents the relationship of the angular speed time derivative with the other variables implied in the structure of the model is obtained.

To end the mathematical definition of the model, only the motor torque equation needs to be described. Motor internal torque is not directly calculated. It is obtained from the load torque and the motor angular speed:

$$
T-T_{L O A D}-k_{r} w_{r}=J \frac{d w_{r}}{d t}
$$

- $\quad T$ : motor electromagnetic torque.

- $T_{L O A D}$ : load torque.

- $k_{r} w_{r}$ : load torque caused by friction losses.

- $J$ : moment of inertia of motor and load.

\section{Model Results}

Although the aim of the model is to be applied for motor fault diagnosis (rotor asymmetries and interturn stator shortcircuits) in this preliminary study only normal operating conditions have been simulated, in order to check the model accuracy. The following figures show a summary of the obtained results. All the simulated variables presented an excellent agreement with experimental measurements and data provided by the motor manufacturer.

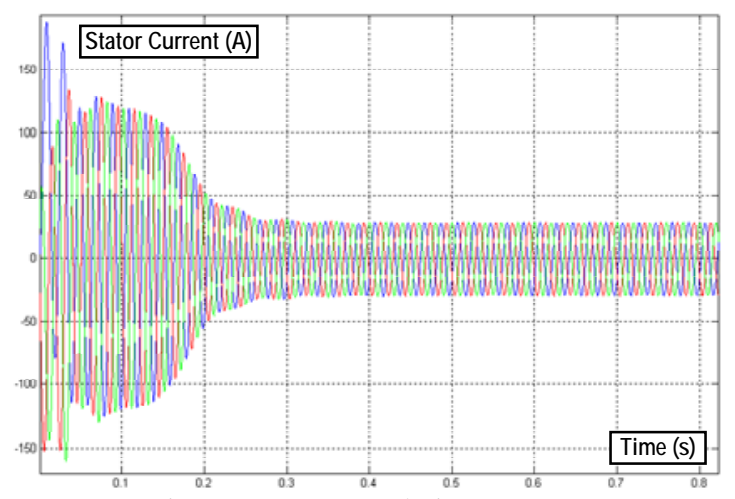

Fig. 8 Stator current during a start up

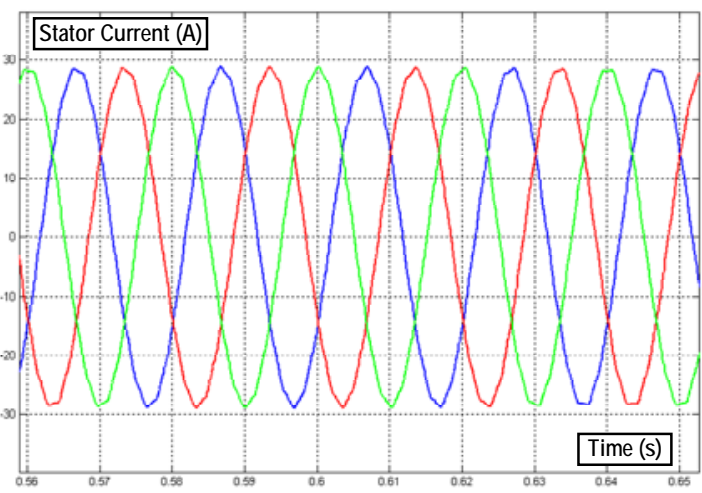

Fig. 9 Steady state stator current (zoom view)

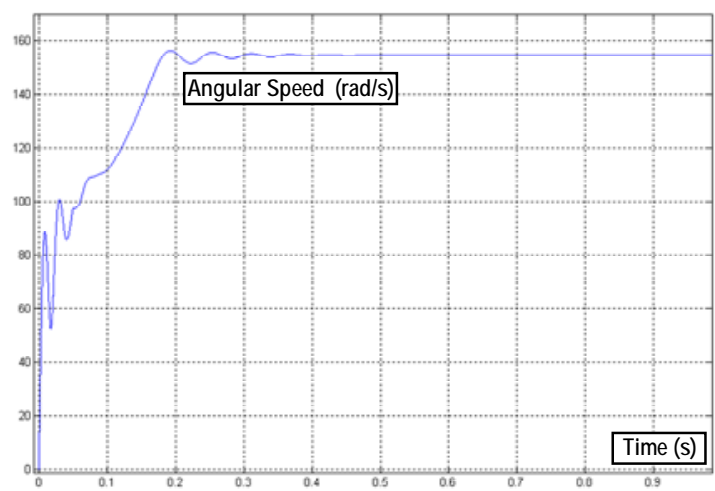

Fig. 10 Angular speed during a start up

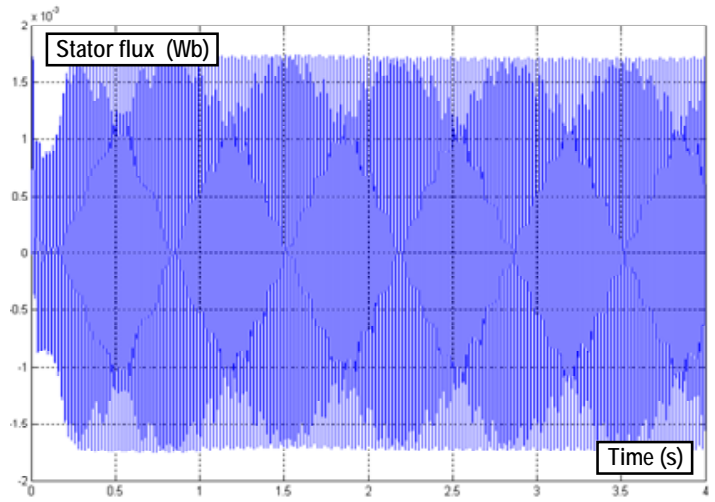

Fig. 11 Magnetic flux in a stator tooth

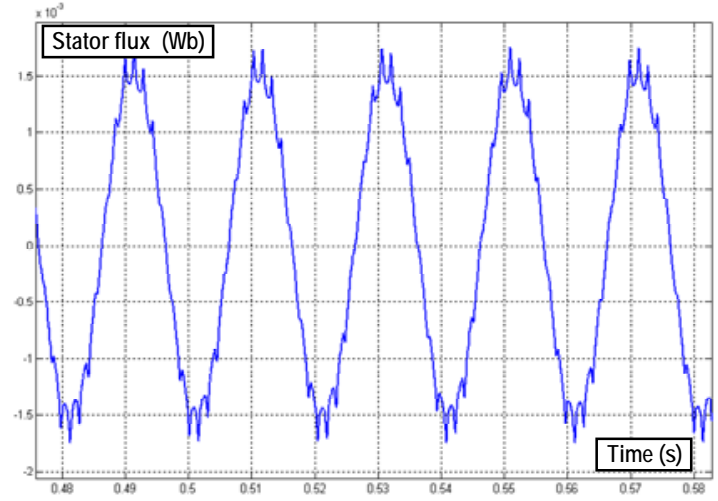

Fig. 12 Magnetic flux in a stator tooth (zoom view) 


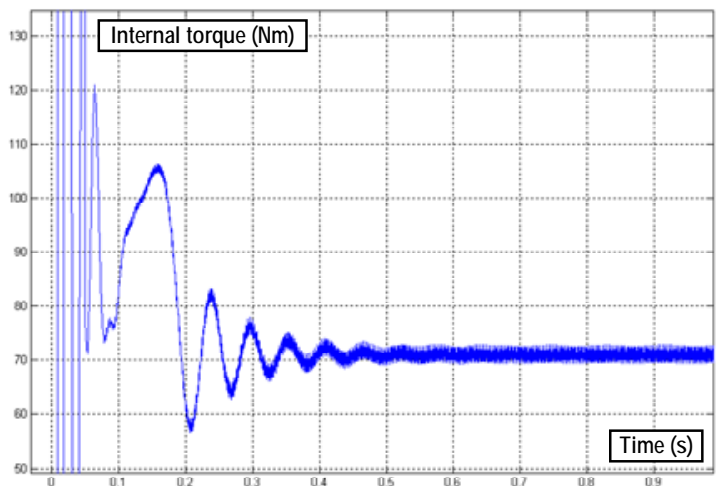

Fig. 13 Electromagnetic torque during a start up

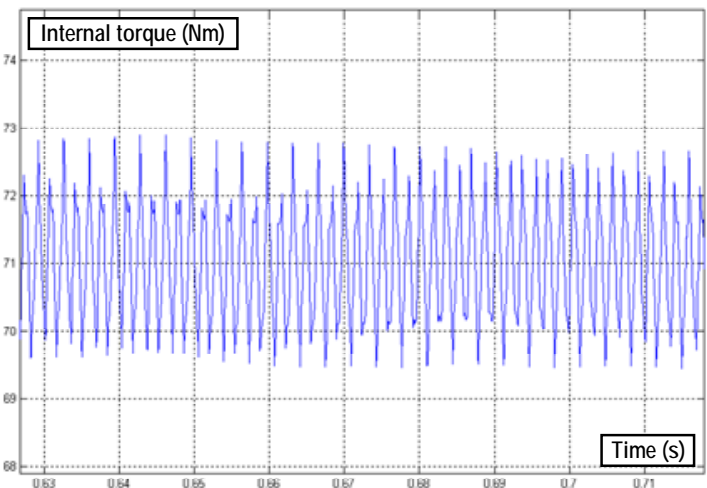

Fig. 14 Electromagnetic torque in steady state (zoom view)

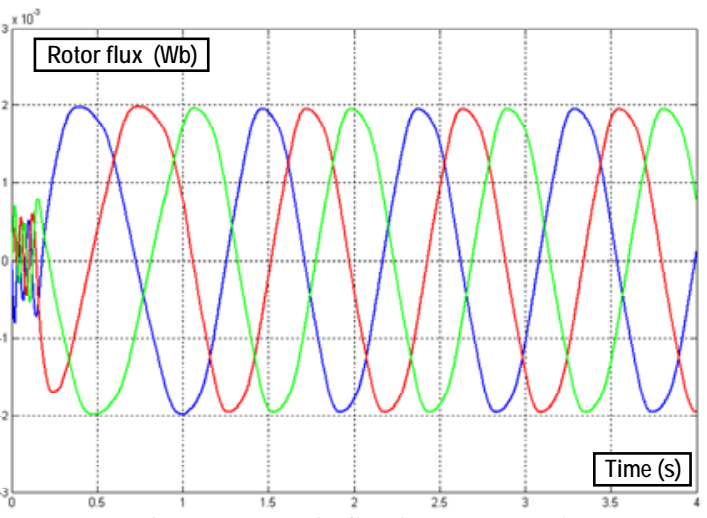

Fig. 15 Magnetic flux in a rotor tooth

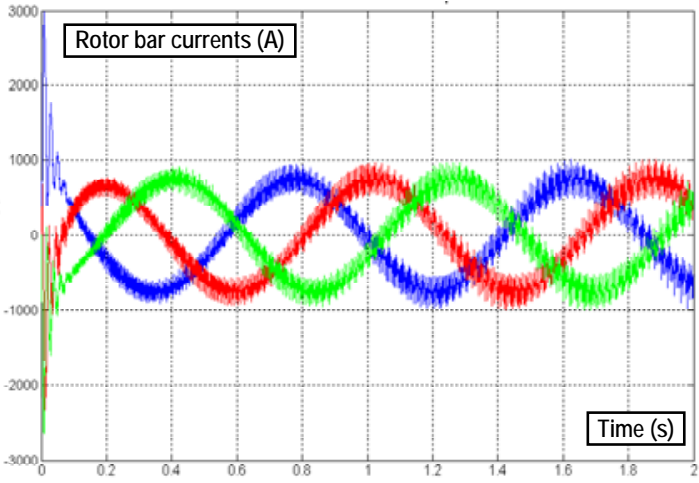

Fig. 16 Current through three rotor bars

\section{Conclusions}

The developed model allows the dynamic simulation of the main variables of an induction motor with a great hardware resources economy, as well as a very low processing time. However, very relevant aspects of machine behaviour such as magnetic saturation and armature reaction have not been neglected, as it is usual in other models. The model is very flexible and can be easily modified in order to introduce fault conditions. The preliminary results have been checked with laboratory measurements over the simulated motor and allowed the verification of model accuracy and reliability.

\section{References}

[1] M. F. Cabanas et Al., "Maintenance and diagnosis techniques for rotating electric machinery" Edt. ABB ISBN 84-267-1222-3. 1999.

[2] M. Derrhi, C. Delmotte-Delforge, P. Brochet: "Fault simulation of induction machines a coupled permeance network model". The 1999 IEEE International symposium on diagnostics for electrical machines, power electronics and drives, Pag 401.ISNB: 84-6990977-0.

[3] H.A. Toliyat and T. A. Lipo, "Transient analysis of cage induction machines under stator, rotor bar and end ring faults”, IEEE Trans. Energy Convers., vol 10, $\mathrm{n}^{\circ} 2$, pp 241-247, Junio 1995.

[4]: Luo, X.,Liao, Y. Toliyat, H.,El-Antably, A., Lipo, T. Multiple coupled circuit modeling of induction machines. Industry Applications Society. 28th Annual Meeting (IAS 93), Vol. 2, Toronto, 1993. pp 203-210.

[5] Salon, S. "Finite Element Analysis of Electrical Machines”. Edt. Krhuwer A. Publisher. Boston 1995

[6] C. Rojas et Al. "New data about the current distribution in the rotor of squirrel-cage asynchronous motors after a bar breaking”. IEEE Sdemped'01. Gorizia Italy - September 2001.

[7] J. Bangura, "Diagnosis and Characterization of effects of broken bars and connectors in squirrel-cage induction motors by time-stepping coupled finite element-state space modeling approach". IEEE Transactions on Energy Conversion, Vol. 14, No.4, December 1999.

[8] Plonus M. Electromagnetismo Aplicado. Edt. Reverté S.A. Barcelona, 1992.

[9] Kartashov, A.P., Ecuaciones Diferenciales Ordinarias y fundamentos de Cálculo Variacional. Edt. Reverté, Barcelona 1980.

[10] Steven C. Chapra, Ph. D., Raymond P. Canale, Ph.D. "Métodos numéricos para ingenieros, con aplicaciones en computadoras personales”. Edt. McGraw-Hill, 1990.

[11] Forsythe, G., M. Malcolm, and C. Moler, Computer Methods for Mathematical Computations, Prentice-Hall, New Jersey, 1977. 